\title{
Intramolecular Cycloalkylation of Pyrrole in Ionic Liquids and Immobilized Ionic Liquids ${ }^{\dagger}$
}

\author{
Yogesh R. Jorapur and Dae Yoon Chi \\ Department of Chemistry, Sogang University, 35 Baekbeomro Mapogu, Seoul 121-742, Korea. *E-mail: dychi@sogang.ac.kr \\ ¿Department of Chemical Engineering, Nara National College of Technology, 22 Yata Yamatokoriyama, Nara 639-1080, Japan. \\ Received February 7, 2011, Accepted March 18, 2011
}

Key Words : Pyrrole $C$-alkylation, Intramolecular cycloalkylation, Ring-closure cyclization, Ionic liquid, Immobilized ionic liquid, 5,6,7,8-tetrahydropyrrolo[1,2- $a$ ]pyridine, Friedel-crafts reaction

The formation of C-C bonds-the basic building blocks of molecules is the most significant chemical phenomena in chemistry. Friedel-Crafts alkylation is among the one in the construction of C-C bond. ${ }^{1}$ The alkylation of aromatic rings via Friedel-Crafts alkylation is well established. ${ }^{2}$ An intramolecular form of the Friedel-Crafts alkylation has become an effective method for the rapid construction of many carbo- and heterocyclic compounds. ${ }^{3}$ However, due to high reactivity the reaction in certain fused ring systems were found to be of less benefit. ${ }^{4}$ Also, heterocyclic rings tend to be poor substrates for the Friedel-Crafts reaction. ${ }^{5}$

Over a past decade, ionic liquids ${ }^{6}$ (ILs, Figure 1) have gained tremendous potential as a solvent over conventional organic solvents in many organic reactions including nucleophilic substitution reactions. ${ }^{7}$ Song et al. ${ }^{8}$ have recently reported metal triflate catalyzed Friedel-Crafts alkylation of aromatic compounds with alkenes and alkynes in hydrophobic ILs. Also recently, we have demonstrated that ILs enhance pyrrole $C$-alkylation regioselectively at $\mathrm{C} 2$ position via nucleophilic substitution reaction. ${ }^{9}$ Further, our group reported the synthesis of chromane derivatives using intramolecular Friedel-Crafts reaction in IL. ${ }^{10}$

In addition, immobilizing IL onto solid supports is the growing field of interest due to easier separation of the catalyst from the reaction media and its possible utilization of the catalyst in a continuous system. ${ }^{11}$ Further, polymer forms of ILs were found to have exceptional properties such as stability, electrochemical activity, and high ionic conductivity. ${ }^{12}$ Our group has designed a polystyrene supported ionic liquid $^{13}$ (PSIL, Figure 1) $)^{14}$ that can be used for nucleophilic substitution reactions. In extension of our program on alkylations of heteroarenes in IL media, ${ }^{15}$ herein, we wish to report cycloalkylation of pyrrole in IL and PSIL as two ecofriendly protocols.

Table 1 illustrates intramolecular pyrrole $C$-alkylation of 1-(4-bromobutyl)-1H-pyrrole (1a) under various reaction conditions. Our initial investigation begins with the entry 1 where the cyclization is performed at the temperature of $100{ }^{\circ} \mathrm{C}$ in aprotic organic solvent like acetonitrile without any IL. The

This paper is dedicated to Professor Eun Lee on the occasion of his honourable retirement. reaction afforded $23 \%$ of 5,6,7,8-tetrahydropyrrolo[1,2-a]pyridine $2 \mathbf{a}^{16,17}$ after $24 \mathrm{~h}$. Next, we have performed the same reaction in $\mathrm{IL},[\mathrm{bmim}]\left[\mathrm{SbF}_{6}\right]$ in the absence of co-solvent. We observed dark-brown coloration within $1 \mathrm{~h}$. The reaction mixture on thin-layer chromatography showed absence of starting material however, the reaction provided uncharac-

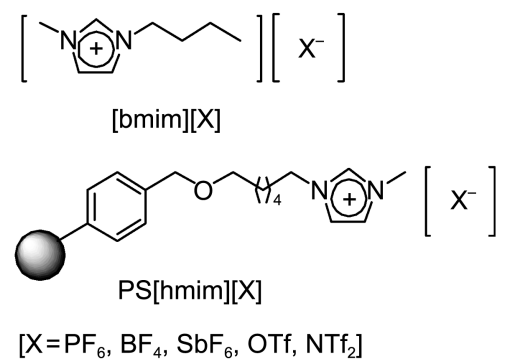

Figure 1. Structure of ILs and PSIL.

Table 1. Intramolecular $C$-alkylation of pyrrole with 1-(4-bromobutyl)$1 H$-pyrrole (1a) under various reaction conditions ${ }^{a}$

\begin{tabular}{|c|c|c|c|c|}
\hline & $1 a$ & & & \\
\hline \multirow{2}{*}{ entry } & \multirow{2}{*}{$\begin{array}{c}\text { [bmim }]\left[\mathrm{SbF}_{6}\right] \\
\mathrm{g} \text { (equiv) }\end{array}$} & \multirow{2}{*}{$\begin{array}{l}\text { time } \\
(\mathrm{h})\end{array}$} & \multicolumn{2}{|c|}{ yield $(\%)^{b}$} \\
\hline & & & 1a & $2 a$ \\
\hline $1^{c}$ & - & 24 & 68 & 23 \\
\hline $2^{d}$ & $1.87(5)$ & 2 & - & - \\
\hline 3 & $1.87(5)$ & 22 & - & 89 \\
\hline 4 & $0.75(2)$ & 38 & trace & 88 \\
\hline 5 & {$[\mathrm{bmim}]\left[\mathrm{BF}_{4}\right](0.55)$} & 48 & 40 & 45 \\
\hline $6^{e}$ & {$[\mathrm{bmim}]\left[\mathrm{BF}_{4}\right](5)$} & 22 & trace & 86 \\
\hline $7^{e}$ & {$[\mathrm{bmim}]\left[\mathrm{PF}_{6}\right](5)$} & 20 & - & 88 \\
\hline 8 & [bmim][OTf] (5) & 24 & - & 88 \\
\hline 9 & {$[\mathrm{bmim}]\left[\mathrm{NTf}_{2}\right](5)$} & 24 & - & 86 \\
\hline
\end{tabular}

${ }^{a}$ All reactions were carried out on a $1.0 \mathrm{mmol}$ reaction scale of 1-(4bromobutyl)-1 $\mathrm{H}$-pyrrole (1a) with $1.0 \mathrm{mmol} \mathrm{NaHCO}$ in $2.0 \mathrm{~mL}$ of $\mathrm{CH}_{3} \mathrm{CN}$ at $100^{\circ} \mathrm{C}$.

${ }^{b}$ Isolated yield.

${ }^{c}$ Reaction in the absence of ionic liquid.

${ }^{d}$ Reaction in the absence of co-solvent acetonitrile; Uncharacterized substance. ${ }^{e}$ Trace of pyrrole was detected by ${ }^{1} \mathrm{H}$ NMR. 
terized substance after workup (entry 2).

Interestingly, the same reaction under identical condition in the presence of co-solvent completed within $24 \mathrm{~h}$ affording $89 \%$ of cyclized product 2a (entry 3). The significant difference in the observation between entries 2 and 3 indicates the need of appropriate amount of co-solvent. In short, dilution of the reaction mixture is requisite for this reaction to proceed. To further optimize the conditions for intramolecular $C$-alkylation of pyrrole, the reactions were run in four other ILs. In entry 5 with 0.55 equiv of $[\mathrm{bmim}]\left[\mathrm{BF}_{4}\right]$, the reaction was found to be slower and provided $\mathbf{2 a}$ in moderate yields. Further, in entries 6-9, 5.0 equiv of $\left[\mathrm{bmim}^{-}\right]\left[\mathrm{BF}_{4}\right],\left[\mathrm{bmim}^{-}\left[\mathrm{PF}_{6}\right]\right.$, [bmim][OTf], and [bmim] $\left[\mathrm{NTf}_{2}\right]$ each were used as ILs and consistent results were obtained to give desired product $\mathbf{2 a}$ in $86,88,88$, and $86 \%$ yields, respectively. These findings clearly indicate that the change of counter anion does not alter much the rate of intramolecular $C$-alkylation of pyrrole.

Alkylation reaction was next performed in the presence of ionic resin, $\mathrm{PS}[\mathrm{hmim}]\left[\mathrm{BF}_{4}\right](2.2 \mathrm{mmol} / \mathrm{g})$ as our second protocol. Interestingly, the reaction proceeded successfully with high yields (Table 2 ).

Entry 1, with 0.11 equiv of resin reached completion in 48 $\mathrm{h}$ to yield $88 \%$ of desired product $\mathbf{2 a}$. Increase in catalyst loading enhanced the reaction rate and the reaction time was reduced to $35 \mathrm{~h}$ (entries 1-3). We further studied the correlation between PSIL and two solvents other than acetonitrile. After $24 \mathrm{~h}$ of stirring the desired product 2 a was obtained in $35 \%$ yield in tert-butanol; $30 \%$ yield in 1,2-dioxane as solvents (entries 5 and 6). These results clearly indicate the effect of solvent on the conversion of $\mathbf{1 a}$ to product $\mathbf{2 a}$.

Further, we have investigated series of substrates to achieve various ring closure systems (Table 3 ). In our initial studies, we observed poor reactivity in the case of chloro substrate 1c whereas, iodo substrate $\mathbf{1 b}$ proceeded to completion in the presence of both $[\mathrm{bmim}]\left[\mathrm{SbF}_{6}\right]$ and $\mathrm{PS}[\mathrm{hmim}]\left[\mathrm{BF}_{4}\right]$ (entry 1,

Table 2. Intramolecular $C$-alkylation of pyrrole with 1-(4-bromobutyl) $-1 H$-pyrrole (1a) in the presence of PS $[\mathrm{hmim}]\left[\mathrm{BF}_{4}\right]$ under various reaction conditions ${ }^{a}$

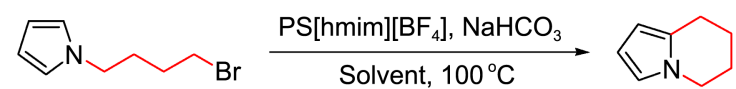

$1 \mathrm{a}$

$2 a$

\begin{tabular}{cccccc}
\hline \multirow{2}{*}{ entry } & $\begin{array}{c}\mathrm{PS}[\mathrm{hmim}]\left[\mathrm{BF}_{4}\right] \\
\text { mg (equiv) }\end{array}$ & $\begin{array}{c}\mathrm{CH}_{3} \mathrm{CN} \\
(\mathrm{mL})\end{array}$ & $\begin{array}{c}\text { time } \\
(\mathrm{h})\end{array}$ & \multicolumn{2}{c}{ yield $(\%)^{b}$} \\
\cline { 5 - 7 } 1 & $50(0.11)$ & 2 & 48 & trace & $\mathbf{2 a}$ \\
2 & $250(0.55)$ & 2 & 40 & - & 89 \\
3 & $500(1.1)$ & 4 & 35 & trace & 89 \\
$4^{c}$ & $500(0.11)$ & 4 & 56 & - & 88 \\
$5^{d}$ & $250(0.55)$ & $t$-BuOH & 24 & 50 & 35 \\
$6^{d}$ & $250(0.55)$ & 1,4-dioxane & 24 & 54 & 30 \\
\hline
\end{tabular}

${ }^{a}$ All reactions were carried out on a $1.0 \mathrm{mmol}$ reaction scale of 1-(4bromobutyl)- $1 \mathrm{H}$-pyrrole (1a) with $1.0 \mathrm{mmol} \mathrm{NaHCO}$ in $\mathrm{CH}_{3} \mathrm{CN}$ at $100{ }^{\circ} \mathrm{C}$. ${ }^{b}$ Isolated yield and equiv indicates the amount of IL portion, not ionic resin.

${ }^{c}$ IL portion per gram of polymer-supported IL used was $0.73 \mathrm{mmol}$.

${ }^{d}$ Solvent used was $2.0 \mathrm{~mL}$.
Table 3. Intramolecular $C$-alkylations of pyrroles with various alkyl halides in the presence of $[\mathrm{bmim}]\left[\mathrm{SbF}_{6}\right]$ and $\mathrm{PS}[\mathrm{hmim}]\left[\mathrm{BF}_{4}\right]$ under various reaction conditions

\begin{tabular}{|c|c|c|c|c|c|}
\hline \multirow[b]{2}{*}{ entry } & \multirow[b]{2}{*}{ substrate } & \multicolumn{2}{|c|}{$[\mathrm{bmim}]\left[\mathrm{SbF}_{6}\right]^{a}$} & \multicolumn{2}{|c|}{$\mathrm{PS}[\mathrm{hmim}]\left[\mathrm{BF}_{4}\right]^{b}$} \\
\hline & & time $(\mathrm{h})$ & $\begin{array}{l}\text { product } \\
(\%)^{c}\end{array}$ & time (h) & $\begin{array}{l}\text { product } \\
(\%)^{c}\end{array}$ \\
\hline 1 & & 15 & $\mathbf{2 a}(52)$ & 31 & $2 \mathbf{a}(58)$ \\
\hline 2 & & 24 & $\mathbf{2 a}(8)$ & 24 & $\mathbf{2 a}(12)$ \\
\hline $3^{d}$ & & 24 & - & 24 & - \\
\hline 4 & & 24 & 2e (22) & 24 & $2 \mathrm{e}(27)$ \\
\hline 5 & & 24 & $\mathbf{2 f}$ (trace) & 24 & $2 \mathbf{f}$ (trace) \\
\hline
\end{tabular}

${ }^{a}$ Reactions were carried out on a $1.0 \mathrm{mmol}$ reaction scale of $1-(\omega-$ bromoalkyl)- $1 H$-pyrrole (1) in the presence of $1.0 \mathrm{mmol} \mathrm{NaHCO}_{3}$, [bmim] $\left[\mathrm{SbF}_{6}\right]$ (5.0 equiv) in $2.0 \mathrm{~mL}$ of $\mathrm{CH}_{3} \mathrm{CN}$ at $100^{\circ} \mathrm{C}$.

${ }^{b}$ Reactions were carried out on a $1.0 \mathrm{mmol}$ reaction scale of $1-(\omega-$ bromoalkyl)-1H-pyrrole (1) in the presence of $1.0 \mathrm{mmol} \mathrm{NaHCO}_{3}$, PS $[\mathrm{hmim}]\left[\mathrm{BF}_{4}\right]$ (1.1 equiv) in $4.0 \mathrm{~mL}$ of $\mathrm{CH}_{3} \mathrm{CN}$ at $100{ }^{\circ} \mathrm{C}$ and equiv indicates the amount of IL portion, not ionic resin.

${ }^{c}$ Isolated yield.

${ }^{d}$ Starting material was recovered.

52 and 58\% yields, respectively). While 5- and 8-membered ring formation were found to be unsuccessful from 1d and 1f, respectively (entries 3 and 5) whereas, 7-membered ring formation was achieved in low yield (entry 4 ).

The venerable intramolecular $C$-alkylation reaction in pyrrole is normally catalyzed by Lewis acids with the generation of toxic waste. However, our methodology is free from any Lewis acid, where the reaction media IL and PSIL themselves catalyzes intramolecular $C$-alkylation.

In summary, the work described here employs IL and PSIL as two eco-friendly media to achieve intramolecular $C$ alkylation in pyrrole, resulting excellent yields of ring closure (6-membered) product. 1-(4-Bromobutyl)-1H-pyrrole (1a) is used as a model substrate to afford 5,6,7,8-tetrahydropyrrolo [1,2-a]pyridine (2a) in 89\% yield. Our methodology is simple and devoid of Lewis acid. Work-up procedure is convenient in the case of both IL and PSIL protocols.

\section{Experimental Section}

Typical Procedure for Intramolecular Pyrrole $C$-Alkylation in Ionic Liquid.

5,6,7,8-Tetrahydropyrrolo $[1,2-a]$ pyridine (2a): 1-(4Bromobutyl)-1 $H$-pyrrole (1a, $202 \mathrm{mg}, 1.0 \mathrm{mmol}$ ) was added to a mixture of $\mathrm{NaHCO}_{3}(84 \mathrm{mg}, 1.0 \mathrm{mmol})$ and $[\mathrm{bmim}]\left[\mathrm{SbF}_{6}\right]$ $(750 \mathrm{mg})$ in acetonitrile $(2.0 \mathrm{~mL})$. The mixture was stirred over $38 \mathrm{~h}$ at $100{ }^{\circ} \mathrm{C}$. The reaction mixture was extracted from ionic liquid phase with ethyl ether $(10 \mathrm{~mL} \times 5)$. The organic 
layer was dried over anhydrous sodium sulfate and evaporated under reduced pressure. The residue was purified by flash column chromatography (silica gel) (5\% EtOAc/hexanes) to obtain of 5,6,7,8-tetrahydropyrrolo [1,2-a] pyridine (2a, 106 $\mathrm{mg}, 88 \%$ ) as a colorless liquid: ${ }^{1} \mathrm{H} \mathrm{NMR}\left(400 \mathrm{MHz}, \mathrm{CDCl}_{3}\right) \delta$ 1.81-2.00 (m, 4H), 2.75-2.85 (m, 2H), 3.89-4.02 (m, 2H), 5.84-5.85 (m, 1H), 6.13-6.15 (m, 1H), 6.52-6.54 (m, $1 \mathrm{H}) ;{ }^{13} \mathrm{C}$ NMR $\left(100 \mathrm{MHz}, \mathrm{CDCl}_{3}\right) \delta 21.5,23.3,23.9,45.3,103.8$, 107.4, 118.5, 129.1; MS (EI) $121\left(\mathrm{M}^{+}, 100\right)$; Registry No. $13618-88-7$.

6,7,8,9-Tetrahydro-5H-pyrrolo[1,2-a]azepine (2e): ${ }^{16}$ light yellow solid: m.p. $36-37{ }^{\circ} \mathrm{C} ;{ }^{1} \mathrm{H}$ NMR $\left(400 \mathrm{MHz} \mathrm{CDCl}_{3}\right) \delta$ $1.63-1.66(\mathrm{~m}, 2 \mathrm{H}), 1.73-1.79(\mathrm{~m}, 4 \mathrm{H}), 2.71(\mathrm{t}, J=5.6 \mathrm{~Hz}$, $2 \mathrm{H}), 3.91(\mathrm{t}, J=5.6 \mathrm{~Hz}, 2 \mathrm{H}), 5.85-5.87(\mathrm{~m}, 1 \mathrm{H}), 5.94-5.95(\mathrm{~m}$, 1H), 6.49-6.51 (m, 1H); $\left.{ }^{13} \mathrm{C} \mathrm{NMR} \mathrm{(100} \mathrm{MHz,} \mathrm{CDCl}_{3}\right) \delta 28.1$, 28.3, 29.8, 31.1, 50.2, 105.5, 106.3, 121.0, 135.3; MS (EI) 135 $\left(\mathrm{M}^{+}, 100\right)$; Registry No. 13618-89-8.

Typical Procedure for Intramolecular Pyrrole $C$-Alkylation Using Polymer-Supported Ionic Liquid. The procedure is same using polymer-supported ionic liquid except that PS $[\mathrm{hmim}]\left[\mathrm{BF}_{4}\right](500 \mathrm{mg}, 1.1 \mathrm{mmol})$ in $\mathrm{CH}_{3} \mathrm{CN}(4.0 \mathrm{~mL})$ was used and after completion the reaction mixture was filtered and washed with ethyl acetate. The filtrate was dried over anhydrous sodium sulfate and evaporated in vacuo. The residue was purified by short flash column chromatography.

Acknowledgments. This research was supported by the Converging Research Program (2010K001050) and by the Real-Time Molecular Imaging Project (NRF, 2009-0065588) through the Ministry of Education, Science and Technology.

Supporting Information. Characterization of all compounds including ${ }^{1} \mathrm{H}$ and ${ }^{13} \mathrm{C}$ NMR spectra (10 pages) are available on request from the correspondence authors. Fax: +82-2-7152411; E-mail: dychi@sogang.ac.kr.

\section{References and Notes}

1. (a) Olah, G. A.; Kishnamurti, R.; Prakash, G. K. S. In Comprehensive Organic Synthesis; Trost, B. M., Fleming, I., Eds.; Pergamon Press: Oxford, 1991; Vol. 3, pp 293-300. (b) Olah, G. A. In Friedel-Crafts and Related Reactions; Wiley-Interscience: New York, 1964, Vol. 2, Part 1, pp 1031, 658, and 703.

2. (a) Adams, C. J.; Earle, M. J.; Roberts, G.; Seddon, K. R. Chem. Commun. 1998, 2097-2098. (b) Barluenga, J.; Tomás, M.; SuárezSobrino, A.; Rubio, E. J. Org. Chem. 1993, 58, 700-704. (c) Roberts, R. M.; Anderson, G. P.; Khalaf, A. A., Jr.; Low, C.-E. J. Org. Chem. 1971, 36, 3342-3345. (d) Khalaf, A. A., Jr.; Roberts, R. M. J. Org. Chem. 1972, 37, 4227-4235.

3. (a) Beck, J. R.; Booher, R. N.; Brown, A. C.; Kwok, R.; Pohland, A. J. Am. Chem. Soc. 1967, 89, 3934-3935. (b) Conley, R. T.; Knopka, W. N. J. Org. Chem. 1964, 29, 496-497. (c) Majetich, G.; Zhang, Y. J. Am. Chem. Soc. 1994, 116, 4979-4980.

4. Smith, M. D.; March, J. In Advanced Organic Chemistry, 5th ed.; Wiley-Interscience: New York, 2001; pp 707-711.
5. (a) Schriesheim, A. In Friedel-Crafts and Related Reactions; Vol. 2, Olah, G. A., Ed:, Wiley-Interscience: New York, 1964; Chapter XVII. (b) Patinkin, S. H.; Friedman, B. S. In Friedel-Crafts and Related Reactions; Vol. 2, Olah, G. A., Ed.; Wiley-Interscience: New York, 1964; Chapter XIV.

6. For recent reviews on ionic liquids, see: (a) Sheldon, R. Chem. Commun. 2001, 2399-2407. (b) Zhao, H.; Malhotra, S. V. Aldrichimica Acta 2002, 35, 75-83. (c) Wasserscheid, P.; Keim, W. Angew. Chem., Int. Ed. 2000, 39, 3772-3789. (d) Welton, T. Chem. Rev. 1999, 99, 2071-2083. (e) Jorapur, Y. R.; Chi, D. Y. Bull. Korean Chem. Soc. 2006, 27, 345-354. (f) J. Dupont, R. F. de Souza, P. A. Z. Suarez, Chem. Rev. 2002, 102, 3667-3692. (g) J. Dupont, P. A. Z. Suarez, Phys. Chem. Chem. Phys. 2006, 8, 24422452. (h) For article on [bmim] $\left[\mathrm{BF}_{4}\right]$, see: Jorapur, Y. R. Synlett 2004, 746-747. (i) For article on ILs, see: Rogers, R. D.; Seddon, K. R. Science 2003, 302, 792-793.

7. (a) Kim, D. W.; Song, C. E.; Chi, D. Y. J. Am. Chem. Soc. 2002, 124, 10278-10279. (b) Kim, D. W.; Song, C. E.; Chi, D. Y. J. Org. Chem. 2003, 68, 4281-4285. (c) Kim, D. W.; Hong, D. J.; Seo, J. W.; Kim, H. S.; Kim, H. G.; Song, C. E.; Chi, D. Y. J. Org. Chem. 2004, 69, 3186-3189. (d) Boovanahalli, S. K.; Kim, D. W.; Chi, D. Y. J. Org. Chem. 2004, 69, 3340-3344. (e) Jorapur, Y. R.; Chi, D. Y. J. Org. Chem. 2005, 70, 10774-10777.

8. (a) Song, C. E.; Shim, W. H.; Roh, E. J.; Choi, J. H. Chem. Commun. 2000, 1695-1696. (b) Song, C. E.; Jung, D.-u.; Choung, S. Y.; Roh, E. J.; Lee, S.-g. Angew. Chem., Int. Ed. 2004, 43, 6183-6185.

9. Jorapur, Y. R.; Lee, C.-H.; Chi, D. Y. Org. Lett. 2005, 7, 1231-1234.

10. Hong, D. J.; Kim, D. W.; Chi, D. Y. Tetrahedron Lett. 2010, 51, 5456.

11. (a) DeCastro, C.; Sauvage, E.; Valkenberg, M. H.; Hölderich, W. F. J. Catal. 2000, 196, 86-94. (b) Tang, H. D.; Tang, J. B.; Ding, S. J.; Radosz, M.; Shen, Y. Q. J. Polym. Sci. Part A: Polym. Chem. 2005, 43, 1432-1443. (c) Burguete, M. I.; Galindo, F.; GarcíaVerdugo, E.; Karbass, N.; Luis, S. V. Chem. Commun. 2007, 3086-3088.

12. (a) Yoshizawa, M.; Ogihara, W.; Ohno, H. Polym. Adv. Technol. 2002, 13, 589-594. (b) Storey, J. M. D.; Williamson, C. Tetrahedron Lett. 2005, 46, 7337-7339. (c) Gu, Y. L.; Ogawa, C.; Kobayashi, J.; Mori, Y.; Kobayashi, S. Angew. Chem., Int. Ed. 2006, 45, 7217 7220.

13. (a) Kim, D. W.; Chi, D. Y. Angew. Chem., Int. Ed. 2004, 43, 483485. (b) Kim, D. W.; Hong, D. J.; Jang, K. S.; Chi, D. Y. Adv. Syn. Catal. 2006, 348, 1719-1727. (c) Kim, D. W.; Jeong, H.-J.; Lim, S. T.; Sohn, M.-H.; Chi, D. Y. Tetrahedron 2008, 64, 4209-4214. (d) Shinde, S. S.; Lee, B. S.; Chi, D. Y. Tetrahedron Lett. 2008, 49, 4245-4248.

14. Abbreviations: [bmim], 1- $n$-Butyl-3-methylimidazolium; [hmim], 1$n$-hexyl-3-methylimidazolium; [ $\left.\mathrm{SbF}_{6}\right]$, hexafluoroantimonate; $\left[\mathrm{BF}_{4}\right]$, tetrafluoroborate; $\left[\mathrm{PF}_{6}\right]$, hexafluorophosphate; [OTf], trifluoromethanesulphonate; [ $\mathrm{NTf}_{2}$ ], bis(trifluoromethyl)sulphonamide.

15. Jorapur, Y. R.; Jeong, J. M.; Chi, D. Y. Tetrahedron Lett. 2006, 47, 2435-2438.

16. (a) Patterson, J. M.; Brasch, J.; Drenchko, P. J. Org. Chem. 1962, 27, 1652-1659. (b) Pizzorno, M. T.; Albonico, S. M. J. Org. Chem. 1977, 42, 909-910. (c) Katritzky, A. R.; Fali, C. N.; Li, J. Q. J. Org. Chem. 1997, 62, 4148-4154. (d) Amos, R. I. J.; Gourlay, B. S.; Molesworth, P. P.; Smith, J. A.; Sprod, O. R. Tetrahedron 2005, 61, 8226-8230.

17. Gracia, S.; Cazorla, C.; Métay, E.; Pellet-Rostaing, S.; Lemaire, M. J. Org. Chem. 2009, 74, 3160-3163. 